\title{
Light and temperature receptors and their convergence in plants
}

\author{
J. SONG, W. WU, and B. HU* \\ College of Liberal Arts and Science, National University of Defense Technology, \\ Changsha, Hunan 410073, P.R. China
}

\begin{abstract}
Light and temperature are two essential environmental cues for plants, helping to optimize plant body architecture and physiology. To sense a broad spectrum of sun radiation spanning from UV-B to far-red wavelength, plants are equipped with a sophisticated array of photoreceptors, including phytochromes, cryptochromes, phototropins, Zeitlupes, and UV-B photoreceptor UVR8. On the contrary, since the thermodynamic effects extensively affect the molecular and supramolecular structures, it is difficult to identify the entry point or initial receptor of temperature. Even so, several putative temperature sensors have been proposed, such as calcium ion channels, H2A.Z, and the thermodynamic change of plasma membrane fluidity. Considering that many processes in plant respond to irradiance and temperature, scientists devote to finding out the converge point of these environmental cues. As a typical example, circadian rhythm is such an integration point, which receives the signal input of both irradiance and temperature. The updating evidence shows, as an important photoreceptor, phytochrome B acts as temperature sensors via a thermodynamic active state revision. These findings suggest that the studies on light and temperature receptors in plants should not be separated. Their extensive convergence during signalling provides a new direction for understanding the stimuli perception mechanisms.
\end{abstract}

Additional key words: calcium channels, circadian rhythm, cryptochromes, phototropins, phytochromes, Zeitlupes.

\section{Introduction}

As the compensation to their relatively poor mobility (Nakashima et al. 2014), plants adjust their physiological and metabolic processes according to the ever-changing environment (Stavang et al. 2009). Recently, the global climate alterations make the situation worse for plants (Toledo-Ortiz et al. 2014). It is urgent to understand the biological mechanism involved in environmental stimuli perception and subsequent signalling cascades.

Irradiance (Kami et al. 2010) and temperature (Hu et al. 2012, Mittler et al. 2012, Xin et al. 2016) synergistically influence plant physiology, growth, and development, providing plants with valuable locational and seasonal information. Radiation quality is determined by its fluence, wavelength, and duration (Jiao et al. 2007). The temperature information is coded into intensity, duration, and rate (Hasanuzzaman et al. 2013).

Seeds germination, elongation growth, and flowering are three typical processes under the cooperative regulation of irradiance and temperature (Seaton et al. 2015, Kigel 2017). As the initial and crucial stage in plants life cycles (Penfield 2017), seed germination, unpredictable over time and space (Gorai et al. 2011), is affected by biotic and abiotic factors such as temperature (Guan et al. 2009, Tozzi et al. 2014) and irradiance (Motsa et al. 2015, Simlat et al. 2016). After germination, hypocotyl elongation is another plastic physiological exhibition, repressed by low temperature (Miyazaki et al. 2015, Ma et al. 2016) and high irradiance (Kurepin et al. 2010). Conversely, it can be promoted by high temperature and low red:far-red (R/FR) conditions (Proveniers and Van Zanten 2013). Afterwards, the optimal combination of radiation and temperature determines the flowering time for plants (Capovilla et al.

Submitted 7 May 2019, last revision 22 July 2019, accepted 5 August 2019.

Abbreviations: APB - active phyB binding; CCA1 - circadian clock associated 1; CRY - cryptochromes; FMN - flavin mononucleotide; H2A.Z - histone variant; LHY - late elongated hypocotyl; LOV - light oxygen voltage; PHOT - phototropins; PHY - phytochromes; PIF - phytochrome-interacting factor; PRR - peripheral loops; R/FR - red:far-red; TOC1 - timing of cab expression 1; UVR8 - UV-B photoreceptor.

Acknowledgments: We thank Jian Li (Hunan Normal University, China), Weisong Pan (Hunan Agricultural University, China), Dezhi $\mathrm{Wu}$, and Shengguan Cai (Zhejiang University, China) for their technical guidance and assistance.

*Corresponding author; e-mail: hubiru08@nudt.edu.cn 
2014, Fernández et al. 2016). To shift from vegetative stage to reproductive stage with optimal time, information about the temperature (Romera-Branchat et al. 2014, Lee et al. 2010) and day-length (Song et al. 2013, Higuchi et al. 2012) is essential.

For biological processes discussed above, environmental stimuli perception is the first step and the key step. During this initial stage, the structural and functional switch of sensory receptors is critical (Casal and Questa 2018). Therefore, the identification of these biological sensors, as well as their working mechanisms, is fundamental.

This paper is focused on the summarization of light and putative temperature sensors in plants, and introduces the stimuli-response mechanism of these sensors. Subsequent signalling cascades have been well-described in previous reviews (Chamovitz et al. 2008, Franklin 2009, Mittler et al. 2012, Wigge 2013), thus they will not be included here. Afterwards, plant circadian clock is discussed, as a typical example of simultaneous light and temperature signals, and how these two signalling pathways are related. At last, a concise description of thermal reversion of red/far-red light receptor phyB is given, which shows an updating opinion that light and temperature perception in plants not only converge with each other during information transduction, but also associated with each other in the stimuli perception stage by sharing the common biological sensors.

\section{Photoreceptors in plants}

Highly conserved in plants species, photoreceptors are critical for light signal perception and transduction. Wideband of sun radiation is monitored by lightactive molecules, including R/FR light photoreceptors phytochromes, UV-A/blue light absorbing cryptochromes, phototropins, Zeitlupe family, and a UV-B photoreceptor UVR8 (Kong and Okajima 2016, Yin and Ulm 2017).

The R/FR light receptors phytochromes (PHYs; PHYA E in Arabidopsis) had two distinct and interconvertible forms: the red light ( $\mathrm{R} \sim 660 \mathrm{~nm}$ ) absorbing inactive form (Pr), and the far-red light (FR $\sim 730 \mathrm{~nm}$ ) absorbing active form (Pfr) (Lorenzo et al. 2016). After the absorption of a photon, inactive $\mathrm{Pr}$ form is photo-converted into biological active Pfr form, which will be transformed back into the Pr form upon FR stimulus (Ballaré and Pierik 2017) (Fig. 1A). During this photo-induced transformation, one of the double bonds in the chromophore is cis-trans isomerized, resulting in the reorientation between chromophore and polypeptide, as well as the conformational change in the protein three-dimensional structure (Chamovitz et al. 2008). Subsequently, the active Pfr translocates towards nuclei and combines with the phytochrome-interacting factor (PIF) transcriptional regulators family. The translocation of Pfr and its interaction with PIFs then lead to a set of downstream reactions (Franklin 2009) and physiological processes (Hornitschek et al. 2009, Chen and Chory 2011).

Being capable of absorbing 400 - $500 \mathrm{~nm}$ wavebands, the flavin-containing blue light detectors cryptochromes (CRY1-3) (Higuchi et al. 2012, Xu et al. 2018) and two phototropins (PHOT1-2) regulate series of plant processes, such as the seedling de-etiolation, stomatal opening (Webb 2003), and phototropism (Goyal et al. 2013). Before blue-light irradiation, a flavin adenine dinucleotide (FAD) chromophore in cryptochrome stays in an oxidized ground state. Upon blue-light activation, an electron transfer reaction turns the FAD chromophore into a reduction state or a "signaling state" (Fig. $1 B$ ), causing light-regulated interactions between photoreceptor and signalling intermediates (Galvao and Fankhauser 2015).

Phototropins are flavoproteins responsible for bluelight perception, carrying two flavin mononucleotide (FMN) chromophore-binding light oxygen voltage (LOV1 and LOV2) domains (Gyula et al. 2003, Okajima et al. 2014). A light-driven covalent binding of FMN to the LOV1/2 domains (Kennis et al. 2003) initiates the conformational changes and auto-phosphorylation of phototropins (Kasahara 2002) (Fig. 1C), which regulates subsequent signalling steps. Besides, there is a bluelight induced re-localization of phototropins (Kong et al. 2006): In the opposite direction to nuclear-localization of photo-activated Pfr, phot1 targets the cytoplasm and phot2 anchors to Golgi apparatus from their original position in nucleus (Gyula et al. 2003).

Another group of blue light receptors, Zeitlupe family, are also equipped with LOV domain. Similar with phototropins LOV domains, Zeitlupe LOV domains bind to flavins and sense light, affecting the activation of downstream components (Kim et al. 2013).

As the only identified UV-B receptors so far, UVR8
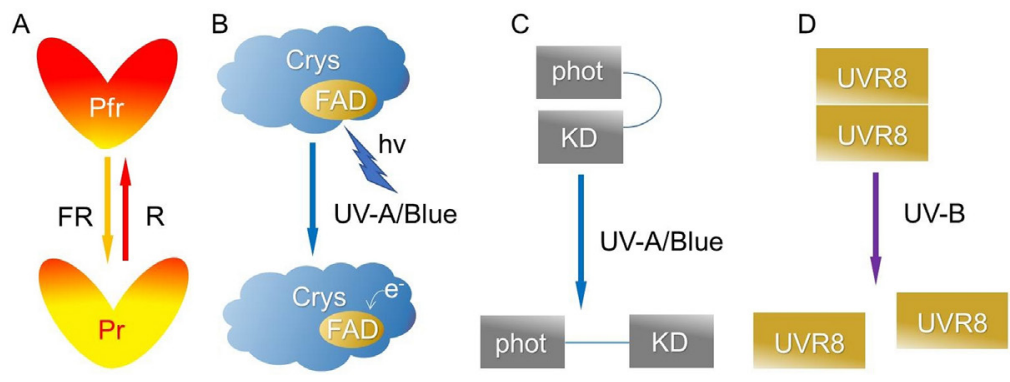

Fig. 1. Light-driven responses of photoreceptors: $A$ - Photoconversation of phytochromes (Pfr:Pr), $B$ - blue light activated electron transfer reaction in crys (FAD chromophore), $C$ - conformational changes of phototropin upon light activation (KD - Ser/Thr kinase domain in the C-terminal region), $D$ - monomerization of UVR8 homodimer upon UV-B stimulus. 
perceives light stimulus with a specific triad of closely packed tryptophan residues (W233, W285, and W337) (Yin and Ulm 2017). In its ground and inactive state, two UVR8 molecules constitute a homodimer, with the force provided by the electrostatic interactions between charged amino acids. In response to UV-B, salt bridges flanking tryptophan triad at the dimer interface are disrupted (Christie et al. 2012), which leads to an instant monomerization of UVR8 homodimer (Rizzini et al. 2011) (Fig. 1D) and signalling initiation (Yin and Ulm 2017).

\section{Temperature perception sensors in plants}

Exposed to high temperature, almost all macromolecules such as protein complexes, membranes, and nucleic acid polymers instantly perceive the heat. In this case, all these macromolecules can be termed as thermosensors, as they respond to temperature alteration by changing their own structure and active forms, or delivering information to associated biological components (Mittler et al. 2012). The heat-induced responses are more complex (Kosova et al. 2015, Legris et al. 2017) than responses to radiation, making it harder to identify thermosensors (Penfield 2008, Miura and Furumoto 2013).

Even so, we are still eager to identify the very initial sensors. They should acquire temperature fluctuation directly from the environment, and regulate large-scale downstream reactions. So far, there are three candidates: temperature-dependent membrane fluidity alterations, calcium channels in the plasma membrane, the histone variant H2A.Z-nuclesome in the nucleus.

An alteration of temperature has direct effect on membrane fluidity. A decrease in temperature causes "rigidification" and lows membrane fluidity, whereas its increase causes "fluidization" and enhances membrane fluidity (Fig. 2A). Subsequently, this physical state change of membrane lipids affects the activity of membranebound proteins, making temperature information delivered (Ruelland and Zachowski 2010). From this dimension, plasma membrane has the potential to be the primary thermal sensor, which perceives and transfers ambient temperature signals (Mittler et al. 2012).

Then, it is speculated that $\mathrm{Ca}^{2+}$ channels act as relayed stations (Murata and Los 1997), which receive messages from dynamic changes of membrane physical states, and adjusts following biological processes (Saidi et al. 2009). They function as fundamental versatile second messengers (Steinhorst and Kudla 2014), relating environmental stimuli with inner cellular machinery. The $\mathrm{Ca}^{2+}$ signal is characterized by transient translocation of $\mathrm{Ca}^{2+}$ from high content compartments (such as vacuole and apoplast) to low content compartment cytosol. This process is elicited by abiotic and biotic factors, including irradiance, temperature, salinity, and osmotic stress. Then the stimulus-associated $\mathrm{Ca}^{2+}$ signature (duration, amplitude, and frequency) is recognized and delivered to the subsequent sensing and responding system
A

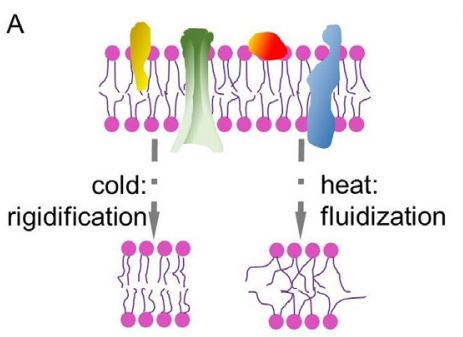

B temperature stimulus or thermal sensors

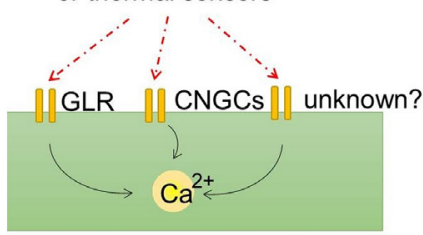

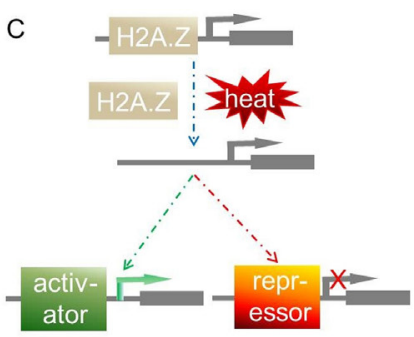

Fig. 2. Putative thermal-sensors and their temperature-driven processes. $A$ - Thermodynamic physical state change of lipid membrane fludity. $B$ - Potential $\mathrm{Ca}^{2+}$ channels on plasma membrane, which "sense" temeprature alteration and send out $\mathrm{Ca}^{2+}$ signal. $C$ - Binding site release of H2A.Z upon high temperature.

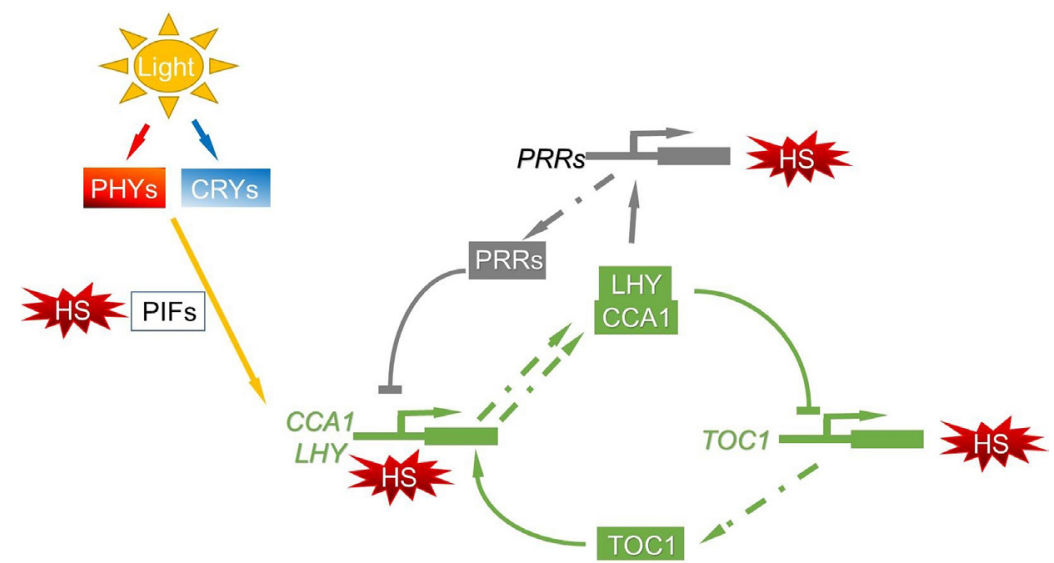

Fig. 3. Central osillator of circadian rhythms in plant. Light signal entries: PHYs and CRYs. Temperature responsive components: PIFs, PRRs, CCA1/LHY, TOC1. 
( $\mathrm{Ca}^{2+}$-binding proteins) (Perochon et al. 2011).

However, the identification of $\mathrm{Ca}^{2+}$ channel is a longlasting and fundamental conundrum in plant research (Steinhorst and Kudla 2014). Emerging evidence indicates that glutamate receptor-like (GLR) and cyclic nucleotidegated channels (CNGCs) take crucial roles in $\mathrm{Ca}^{2+}$ signals in plants (Steinhorst and Kudla 2014, Lorenzo et al. 2016) (Fig. 2B). Beyond that, our knowledge about other potential $\mathrm{Ca}^{2+}$ channels and associated regulation processes is still limited. Even we get more information about $\mathrm{Ca}^{2+}$ channel, there is another question: do these $\mathrm{Ca}^{2+}$ channel associated proteins feel the dynamic physical changes of membrane lipid directly by themselves, or obtain messages from upstream sensory receptors (if exist)?

Another potential thermosensor is the histone variant H2A.Z, which mediates genome-wide transcription changes to ambient temperature (Boden et al. 2013, Proveniers and Van Zanten 2013). Experimental results demonstrated that H2A.Z-containing nucleosomes occupy the -1 position of numerous genes. This occupancy is inversely correlated with temperature intensity. High temperature tends to release H2A.Z from -1 position, leaving that location available for gene promoters or inhibitors. This results in the gene expression promotion or inhibition (Kumar and Wigge 2010) (Fig. 3C). For example, at lower temperatures, H2A.Z nucleosomes have a higher occupancy at PIF4-binding site in the flowering locus $\mathrm{T}$ promoters. As temperature raises, H2A.Z nucleosomes occupancy declines, and PIF4 binding enhances, which promotes the lowering locus $\mathrm{T}$ expression (Proveniers and Van Zanten, 2013 Wigge 2013, Ma et al. 2016).

\section{Temperature inputs into photoperiod-mediated circadian clock in plants}

Jeffrey C. Hall, Michael Rosbash, and Michael W. Young were awarded the Nobel Prize in 2017 for their discoveries of molecular mechanisms controlling the circadian rhythm in Drosophila melanogaster (Sehgal et al. 1995, Price et al. 1998). Their findings fulfill the circadian clock in organisms, and explain how organisms persist diurnal rhythms, even be deprived with exogenous time cues (McClung 2006).

In higher plants, circadian rhythms also work as the bridge between endogenous events with external environmental stimuli (Harmer et al. 2000), defining a time cycle of $24 \mathrm{~h}$ (McClung 2006). This clock regulates various physiological processes, including photoperiodic induction of flowering, rhythmic hypocotyl elongation (Greenham and McClung 2015), and cotyledon movement (Lou et al. 2011). Whereas, the molecular basis underlying plants circadian molecular progresses is different from that in Drosophila.

In the beginning, photoreceptors cryptochromes and phytochromes perceive blue and R/FR radiation signals, and transduce these information into the circadian clock (Oakenfull and Davis 2017). These messages regulate the transcription of three central oscillator elements: late elongated hypocotyl (LHY), circadianclock associated 1 (CCA1), and timing of cab expression 1 (TOC1) via a negative feedback loop (Hemmes et al. 2012, Nohales and Kay 2016). During late evening, CCA1 and LHY transcriptions will be promoted by TOC1, and maximized at dawn. In turn, CCA1 and LHY negatively regulate the expression of TOC1 by binding to its promoter, which weakens the promotion of TOC1 on CCA1/LHY expression during daytime (Niwa et al. 2009). Subsequently, as CCA1 and LHY abundance decrease, their inhibitory effect on TOC1 will be abolished, resulting in the increase of TOC1 at night (Grundy et al. 2015). This central oscillator cooperates with another peripheral loops (PRR5, PRR7, and PRR9 as three TOC1 paralogs) and integrates environmental signals with internal cues to coordinate diverse physiological outputs (Hsu and Harmer 2014).

Interestingly, except for light cycles or pulses, abrupt temperature changes, or temperature cycles can act as potent stimuli to shift the phase of this clock (James et al. 2012). Circadian clock is both entrained to and compensated with temperature (Franklin et al. 2014, Inoue et al. 2017). Our previous work figured out the functional elements during this temperature-dependent circadian rhythm response (Song et al. 2015): upon the heat stress $\left(37^{\circ} \mathrm{C}\right.$ for $\left.30 \mathrm{~min}\right)$, the expression of $C C A 1$, $L H Y$, and PRRS respond to heat stress significantly (Fig. 3). Similar temperature-induced transcription perturbation of circadian rhythm genes has been confirmed (Albihlal et al. 2018, Chen et al. 2018). This indicates that circadian rhythm in plants works as an information hub, which receives regulation messages from both light and temperature. The integrated signal is then used to modulate the large-scale subsequent biological processes.

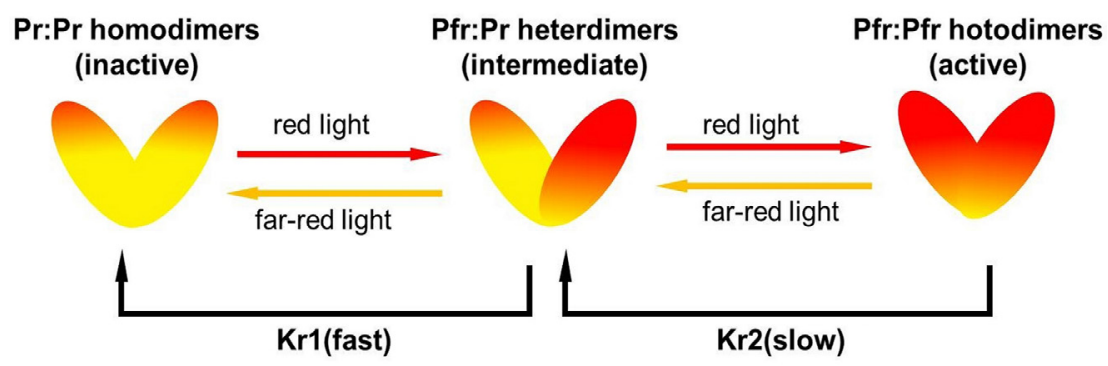

Fig. 4. The phyB active states determined by two aspects: Pr:Pfr reversion upon R/FR light stimulus, and temperature-dependent reversion rate $(\mathrm{Kr} 1 / \mathrm{Kr} 2)$. 


\section{Temperature-dependent phyB reversion}

The above section describes the synergistic effect of light and temperature on circadian rhythm. As an input parameter, temperature adjusts the performance of circadian clock and associated molecule elements. These compounds, including LHY, CCA1, TOC1, and PRRs, not only work within the circadian clock, but also operate outside the loops and interact with PIFs (Hemmes et al. 2012, Leivar and Monte 2014). Will this temperature input eventually be transduced to light signaling pathways via PIFs? Will this input even be delivered to phytochromes? Considering the tight interaction of PIFs and PHYs in the effects on protein activity and gene expression (Smith et al. 2017), this is highly possible. From this dimension, the light receptor phytochromes can be responsive to temperature stimulus, serving as thermal sensors.

Legris et al. (2017) reported a remarkable reduction of biological active Pfr-Pfr dimer abundance and phyB nuclear accumulation under the warmer environment (e. g., $30^{\circ} \mathrm{C}$ ) in Arabidopsis. Interestingly, this phyB pool thermal reversion is light-dependent. At certain irradiance, there is a high proportion of unstable Pfr:Pr heterodimers that can be quickly turned into Pr:Pr homodimers, via full name?? (kr1) (Klose et al. 2015), while in darkness, the thermal reversion via $\mathrm{kr} 2$ (Klose et al. 2015) is much slower (Legris et al. 2016) (Fig. 4).

In the study of Jung et al. (2016), the alteration of phyB active states has a significant effect on temperatureinduced gene responses. Firstly, the binding-site detection via chromatin immunoprecipitation reveal there are more phyB target genes at 17 than at $27{ }^{\circ} \mathrm{C}$. Moreover, most of these genes respond to temperature during night, when phyB stays inactive. This evidence suggests that phyB may act as a repressor of those temperature responsive genes.

Focusing on the dark reversion rate, Jung et al. (2016) reported a significant exponential relationship between temperature and phyB:phyB $B_{\text {fr }}$ half-life: high temperature shortens phyB:phyB $B_{\text {Pfr }}$ half-life and makes them unstable during nighttime. However, Legris et al. (2017) stated that this thermal effect should be more prominent during daytime.

Based on their discoveries, phyB is able to answer temperature changes by altering its own biological states, and regulating its associated genes temperature responses. Therefore, it is fair to define the photo-receptor phyB as a thermal sensor (Delker et al. 2017, Song et al. 2017).

\section{Conclusions}

So far, we have a quite clear picture about light receptors and their signalling pathways in plant. Photoreceptors include R/FR photoreceptors phytochromes, UV-A/blue radiation absorbing cryptochromes, phototropins, and Zeitlupe family members, and a UV-B photoreceptor UVR8. However, the information about upstream thermal sensors is still limited. Although temperature-dependent membrane fluidity, $\mathrm{Ca}^{2+}$ channels, and H2A.Z have been suggested as putative candidates, their temperature perception processes and signalling networks are not fully deciphered.

From a biochemistry point, only those molecules containing chromophores can capture photon with specific energy, and perceive radiation of particular wavelength. This light-driven structural transformation affects the subsequent signalling cascades and associated biological components.

On the contrary, temperature effects on molecule elements are not "specific". Temperature is a basic parameter for biochemical reaction equilibrium, reaction rates, and enzymatic activities. Therefore, the fluctuation of temperature indistinguishably affects the structure and bio-activity of hundred and thousand molecules, regulating the countless biochemical reactions in organisms. In this case, all these macromolecules in plants can be termed as thermosensor, as they are temperature-responsive. Even so, we are still eager to identify those essential biological components, which work as stimuli receiver and signalling pivotal hubs. They should not only obtain temperature information from the environment directly, but also affect large-scale downstream reactions.

Growing in nature and experiencing a considerable complex environment, plants simultaneously receive numerous integrated signals (Wigge 2013). Thus, multisensory systems should work together to deal with these inputs and optimize plant architecture (Casal and Questa 2018). Considering the synergistic effects of light and temperature signals on numerous physiological processes (Bita and Gerats 2013, Hahn et al. 2013, Rasmussen et al. 2013), the molecular mechanisms of photo- and thermo-perception should not be analyzed separately as before (Loveys et al. 2002, Legris et al. 2017). Exploring the coordination of the two environmental signalling transduction cascades will offer a new way to understand the plant response to fluctuations in environment, as well as a new avenue to identify new sensory receptors.

\section{References}

Albihlal, W.S., Obomighie, I., Blein, T., Persad, R., Chernukhin, I., Crespi, M., Bechtold, U., Mullineaux, P.M.: Arabidopsis heat shock transcription factor $\mathrm{Alb}$ regulates multiple developmental genes under benign and stress conditions. - J. exp. Bot. 69: 2847-2862, 2018.

Ballaré, C.L., Pierik, R.: The shade-avoidance syndrome: multiple signals and ecological consequences. - Plant Cell Environ. 40: 2530-2543, 2017.

Bita, C.E., Gerats, T.: Plant tolerance to high temperature in a changing environment: scientific fundamentals and production of heat stress-tolerant crops. - Front. Plant Sci 4: 273, 2013.

Boden, S.A., Kavanová, M., Finnegan, E.J., Wigge, P.A.: Thermal stress effects on grain yield in Brachypodium distachyon occur via H2A.Z-nucleosomes. - Genome Biol. 14: R65, 2013.

Capovilla, G., Schmid, M., Posé, D.: Control of flowering by ambient temperature. - J. exp. Bot. 66: 59-69, 2014.

Casal, J.J., Questa, J.I.: Light and temperature cues: multitasking receptors and transcriptional integrators. - New Phytol. 217: 1029-1034, 2018 
Chamovitz, D.A., Deng, X.W., Lam, E.: Light signaling in plants. - Crit. Rev. Plant Sci. 15: 455-478, 2008.

Chen, H.D., Wang, J., Zhao, M.Z., Zhao, F.: Characterization and expression analysis of circadian clock genes in the diploid woodland strawberry Fragaria vesca. - Biol. Plant. 62: 451$461,2018$.

Chen, M., Chory, J.: Phytochrome signaling mechanisms and the control of plant development. - Trends cell. Biol. 21: 664-671, 2011.

Christie, J.M., Arvai, A.S., Baxter, K.J., Heilmann, M., Pratt, A.J., O'Hara, A., Kelly, S.M., Hothorn, M., Smith, B.O., Hitomi, K., Jenkins, G.I., Getzoff, E.D.: Plant UVR8 photoreceptor senses UV-B by tryptophan-mediated disruption of crossdimer salt bridges. - Science 335: 1492-1496, 2012.

De Lucas, M., Daviere, J.M., Rodriguez-Falcon, M., Pontin, M., Iglesias-Pedraz, J.M., Lorrain, S., Fankhauser, C., Blazquez, M.A., Titarenko, E., Prat, S.: A molecular framework for light and gibberellin control of cell elongation. - Nature 451: 480484, 2008.

Delker, C., Van Zanten, M., Quint, M. : Thermosensing enlightened. - Trends Plant Sci. 22: 185-187, 2017.

Feng, S., Martinez, C., Gusmaroli, G., Wang, Y., Zhou, J., Wang, F., Chen, L., Yu, L., Iglesias-Pedraz, J.M., Kircher, S., Schafer, E., Fu, X., Fan, L.M., Deng, X.W.: Coordinated regulation of Arabidopsis thaliana development by light and gibberellins. Nature 451: 475-479, 2008.

Fernández, V., Takahashi, Y., Le Gourrierec, J., Coupland, G.: Photoperiodic and thermosensory pathways interact through CONSTANS to promote flowering at high temperature under short days. - Plant J. 86: 426-440, 2016.

Franklin, K.A.: Light and temperature signal crosstalk in plant development. - Curr. Opin. Plant Biol. 12: 63-68, 2009.

Franklin, K.A., Lee, S.H., Patel, D., Kumar, S.V., Spartz, A.K., Gu, C., Ye, S., Yu, P., Breen, G., Cohen, J.D., Wigge, P.A., Gray, W.M.: Phytochrome-interacting factor 4 (PIF4) regulates auxin biosynthesis at high temperature. - Proc. nat. Acad. Sci. USA 108: 20231-20235, 2011.

Franklin, K.A., Toledo-Ortiz, G., Pyott, D.E., Halliday, K.J.: Interaction of light and temperature signalling. - J. exp. Bot. 65: 2859-2871, 2014.

Galvao, V.C., Fankhauser, C.: Sensing the light environment in plants: photoreceptors and early signaling steps. - Curr. Opin. Neurobiol. 34: 46-53, 2015.

Gorai, M., Gasmi, H., Neffati, M.: Factors influencing seed germination of medicinal plant Salvia aegyptiaca L. (Lamiaceae). - Saudi J. biol. Sci. 18: 255-260, 2011.

Goyal, A., Szarzynska, B., Fankhauser, C.: Phototropism: at the crossroads of light-signaling pathways. - Trends Plant Sci. 18: 393-401, 2013.

Greenham, K., McClung, C.R.: Integrating circadian dynamics with physiological processes in plants. - Nat. Rev. Genet. 16: 598, 2015.

Grundy, J., Stoker, C., Carré, I.A.: Circadian regulation of abiotic stress tolerance in plants. - Front. Plant Sci. 6: 648, 2015.

Guan, B., Zhou, D., Zhang, H., Tian, Y., Japhet, W., Wang, P.: Germination responses of Medicago ruthenica seeds to salinity, alkalinity, and temperature. - J arid Environ. 73: 135$138,2009$.

Gyula, P., Schäfer, E., Nagy, F.: Light perception and signalling in higher plants. - Curr. Opin. Plant Biol. 6: 446-452, 2003.

Hahn, A., Kilian, J., Mohrholz, A., Ladwig, F., Peschke, F., Dautel, R., Harter, K., Berendzen, K.W., Wanke, D.: Plant core environmental stress response genes are systemically coordinated during abiotic stresses. - Int. J. mol. Sci 14: 7617$7641,2013$.

Harmer, S.L., Hogenesch, J.B., Straume, M., Chang, H.-S., Han,
B., Zhu, T., Wang, X., Kreps, J.A., Kay, S.A.: Orchestrated transcription of key pathways in Arabidopsis by the circadian clock. - Science 290: 2110-2113, 2000.

Hasanuzzaman, M., Nahar, K., Alam, M., Roychowdhury, R., Fujita, M.: Physiological, biochemical, and molecular mechanisms of heat stress tolerance in plants. - Int. J. mol. Sci. 14: 9643-9684, 2013.

Hemmes, H., Henriques, R., Jang, I.-C., Kim, S., Chua, N.-H.: Circadian clock regulates dynamic chromatin modifications associated with Arabidopsis CCA1/LHY and TOC1 transcriptional rhythms. - Plant Cell Physiol. 53: 2016-2029, 2012.

Higuchi, Y., Sumitomo, K., Oda, A., Shimizu, H., Hisamatsu, T.: Day light quality affects the night-break response in the short-day plant chrysanthemum, suggesting differential phytochrome-mediated regulation of flowering. - J. Plant Physiol. 169: 1789-1796, 2012.

Hornitschek, P., Lorrain, S., Zoete, V., Michielin, O., Fankhauser, C.: Inhibition of the shade avoidance response by formation of non-DNA binding bHLH heterodimers. - EMBO J. 28: 3893-3902, 2009.

Hsu, P.Y., Harmer, S.L.: Wheels within wheels: the plant circadian system. - Trends Plant Sci. 19: 240-249, 2014.

Hu, X.W., Huang, X.H., Wang, Y.R.: Hormonal and temperature regulation of seed dormancy and germination in Leymus chinensis. - Plant Growth Regul. 67: 199-207, 2012.

Inoue, K., Araki, T., Endo, M.: Integration of input signals into the gene network in the plant circadian clock. - Plant Cell Physiol. 58: 977-982, 2017.

James, A.B., Syed, N.H., Bordage, S., Marshall, J., Nimmo, G.A., Jenkins, G.I., Herzyk, P., Brown, J.W., Nimmo, H.G.: Alternative splicing mediates responses of the Arabidopsis circadian clock to temperature changes. - Plant Cell 24: 961981, 2012

Jiao, Y., Lau, O.S., Deng, X.W.: Light-regulated transcriptional networks in higher plants. - Nat. Rev. Genet. 8: 217-230, 2007.

Jung, J.-H., Domijan, M., Klose, C., Biswas, S., Ezer, D., Gao, M., Khattak, A.K., Box, M.S., Charoensawan, V., Cortijo, S.: Phytochromes function as thermosensors in Arabidopsis. Science: aaf6005, 2016.

Kami, C., Lorrain, S., Hornitschek, P., Fankhauser, C.: Lightregulated plant growth and development. - In: Timmermans, M.C.P. (ed.): Current Topics in Developmental Biology. Vol. 91. Pp. 29-66. Elsevier, New York 2010.

Kasahara, M.: Photochemical properties of the flavin mononucleotide-binding domains of the phototropins from Arabidopsis, rice, and Chlamydomonas reinhardtii. - Plant Physiol. 129: 762-773, 2002.

Kennis, J.T.M., Crosson, S., Gauden, M., Van Stokkum, I.H.M., Moffat, K., Van Grondelle, R.: Primary reactions of the LOV2 domain of phototropin, a plant blue-light photoreceptor. Biochemistry 42: 3385-3392, 2003.

Kigel, J.: Seed germination in arid and semiarid regions. - In. Kigel, J. (ed.): Seed Development and Germination. Pp. 645699. Routledge, London - New York 2017.

Kim, J., Geng, R., Gallenstein, R.A., Somers, D.E.: The F-box protein ZEITLUPE controls stability and nucleocytoplasmic partitioning of GIGANTEA. - Development 140: 4060-4069, 2013.

Klose, C., Venezia, F., Hussong, A., Kircher, S., Schäfer, E., Fleck, C.: Systematic analysis of how phytochrome B dimerization determines its specificity. - Natur. Plants 1: 15090, 2015.

Koini, M.A., Alvey, L., Allen, T., Tilley, C.A., Harberd, N.P., Whitelam, G.C., Franklin, K.A.: High temperaturemediated adaptations in plant architecture require the bHLH 
transcription factor PIF4. - Curr. Biol. 19: 408-413, 2009.

Kong, S.-G., Okajima, K.: Diverse photoreceptors and light responses in plants. - J. Plant Res. 129: 111-114, 2016.

Kong, S.-G., Suzuki, T., Tamura, K., Mochizuki, N., HaraNishimura, I., Nagatani, A.: Blue light-induced association of phototropin 2 with the Golgi apparatus. - Plant J. 45: 994$1005,2006$.

Kosova, K., Vitamvas, P., Urban, M.O., Klima, M., Roy, A., Prasil, I.T.: Biological networks underlying abiotic stress tolerance in temperate crops - a proteomic perspective. - Int. J. mol. Sci. 16: 20913-20942, 2015.

Kumar, S.V., Wigge, P.A.: H2A.Z-containing nucleosomes mediate the thermosensory response in Arabidopsis. - Cell 140: 136-147, 2010.

Kurepin, L.V., Walton, L.J., Pharis, R.P., Neil Emery, R.J., Reid, D.M.: Interactions of temperature and light quality on phytohormone-mediated elongation of Helianthus annuus hypocotyls. - Plant Growth Regul. 64: 147-154, 2010.

Lee, H., Yoo, S.J., Lee, J.H., Kim, W., Yoo, S.K., Fitzgerald, H., Carrington, J.C., Ahn, J.H.: Genetic framework for floweringtime regulation by ambient temperature-responsive miRNAs in Arabidopsis. - Nucl. Acids Res. 38: 3081-3093, 2010.

Legris, M., Klose, C., Burgie, E.S., Rojas, C.C.R., Neme, M., Hiltbrunner, A., Wigge, P.A., Schäfer, E., Vierstra, R.D., Casal, J.J.: Phytochrome B integrates light and temperature signals in Arabidopsis. - Science 354: 897-900, 2016.

Legris, M., Nieto, C., Sellaro, R., Prat, S., Casal, J.J.: Perception and signalling of light and temperature cues in plants. - Plant J. 90: 683-697, 2017.

Leivar, P., Monte, E.: PIFs: systems integrators in plant development. - Plant Cell 26: 56-78, 2014.

Leivar, P., Quail, P.H.: PIFs: pivotal components in a cellular signaling hub. - Trends Plant Sci. 16: 19-28, 2011.

Lilley, J.L.S., Gee, C.W., Sairanen, I., Ljung, K., Nemhauser, J.L.: An endogenous carbon-sensing pathway triggers increased auxin flux and hypocotyl elongation. - Plant Physiol. 160: 2261-2270, 2012.

Lorenzo, C.D., Sanchez-Lamas, M., Antonietti, M.S., Cerdan, P.D. : Emerging hubs in plant light and temperature signaling. - Photochem. Photobiol. 92: 3-13, 2016.

Lou, P., Xie, Q., Xu, X., Edwards, C., Brock, M., Weinig, C., McClung, C.: Genetic architecture of the circadian clock and flowering time in Brassica rapa. - Theor. appl. Genet. 123: 397-409, 2011.

Loveys, B., Scheurwater, I., Pons, T., Fitter, A., Atkin, O.: Growth temperature influences the underlying components of relative growth rate: an investigation using inherently fast-and slow-growing plant species. - Plant Cell Environ. 25: 975988, 2002.

Ma, D., Li, X., Guo, Y., Chu, J., Fang, S., Yan, C., Noel, J. P., Liu, H.: Cryptochrome 1 interacts with PIF4 to regulate high temperature-mediated hypocotyl elongation in response to blue light. - Proc. nat. Acad. Sci. USA 113: 224-229, 2016.

McClung, C.R.: Plant circadian rhythms. - Plant Cell 18: 792803, 2006.

Mittler, R., Finka, A., Goloubinoff, P.: How do plants feel the heat? - Trends Biochem. Sci. 37: 118-125, 2012.

Miura, K., Furumoto, T. :Cold signaling and cold response in plants. - Int. J. mol. Sci. 14: 5312-5337, 2013.

Miyazaki, Y., Takase, T., Kiyosue, T.: ZEITLUPE positively regulates hypocotyl elongation at warm temperature under light in Arabidopsis thaliana. - Plant Signal Behav. 10: e998540, 2015.

Motsa, M.M., Slabbert, M.M., Van Averbeke, W., Morey, L.: Effect of light and temperature on seed germination of selected African leafy vegetables. - S. Afr. J. Bot. 99: 29-35, 2015.
Murata, N., Los, D.A.: Membrane fluidity and temperature perception. - Plant Physiol 115: 875-879, 1997.

Nakashima, K., Yamaguchi-Shinozaki, K., Shinozaki, K.: The transcriptional regulatory network in the drought response and its crosstalk in abiotic stress responses including drought, cold, and heat. - Front. Plant Sci. 5: 170, 2014.

Niwa, Y., Yamashino, T., Mizuno, T.: The circadian clock regulates the photoperiodic response of hypocotyl elongation through a coincidence mechanism in Arabidopsis thaliana. Plant Cell Physiol. 50: 838-854, 2009.

Nohales, M.A., Kay, S.A.: Molecular mechanisms at the core of the plant circadian oscillator. - Nat. struct. mol. Biol. 23: 1061, 2016.

Oakenfull, R. J., Davis, S. J.: Shining a light on the Arabidopsis circadian clock. - Plant Cell Environ. 40: 2571-2585, 2017.

Okajima, K., Aihara, Y., Takayama, Y., Nakajima, M., Kashojiya, S., Hikima, T., Oroguchi, T., Kobayashi, A., Sekiguchi, Y., Yamamoto, M.: Light-induced conformational changes of LOV1 (light oxygen voltage-sensing domain 1) and LOV2 relative to the kinase domain and regulation of kinase activity in Chlamydomonas phototropin. - J. biol. Chem 289: 413-422, 2014.

Penfield, S.: Temperature perception and signal transduction in plants. - New Phytol. 179: 615-628, 2008.

Penfield, S.: Seed dormancy and germination. - Curr. Biol. 27: R874-R878, 2017.

Perochon, A., Aldon, D., Galaud, J.P., Ranty, B.: Calmodulin and calmodulin-like proteins in plant calcium signaling. Biochimie 93: 2048-2053, 2011

Price, J.L., Blau, J., Rothenfluh, A., Abodeely, M., Kloss, B., Young, M.W.: Double-time is a novel Drosophila clock gene that regulates PERIOD protein accumulation. - Cell 94: 8395, 1998.

Proveniers, M.C., Van Zanten, M.: High temperature acclimation through PIF4 signaling. - Trends Plant Sci. 18: 59-64, 2013.

Rasmussen, S., Barah, P., Suarez-Rodriguez, M.C., Bressendorff, S., Friis, P., Costantino, P., Bones, A.M., Nielsen, H.B., Mundy, J.: Transcriptome responses to combinations of stresses in Arabidopsis. - Plant Physiol. 161: 1783-1794, 2013.

Rizzini, L., Favory, J.-J., Cloix, C., Faggionato, D., O’Hara, A., Kaiserli, E., Baumeister, R., Schäfer, E., Nagy, F., Jenkins, G. I., Ulm, R.: Perception of UV-B by the Arabidopsis UVR8. Science 332: 103-106, 2011.

Romera-Branchat, M., Andres, F., Coupland, G. :Flowering responses to seasonal cues: what's new? - Curr. Opin. Plant Biol. 21: 120-127, 2014.

Ruelland, E., Zachowski, A.: How plants sense temperature. Environ. exp. Bot. 69: 225-232, 2010.

Saidi, Y., Finka, A., Muriset, M., Bromberg, Z., Weiss, Y.G., Maathuis, F.J., Goloubinoff, P.:The heat shock response in moss plants is regulated by specific calcium-permeable channels in the plasma membrane. - Plant Cell 21: 2829-2843, 2009.

Seaton, D.D., Smith, R.W., Song, Y.H., MacGregor, D.R., Stewart, K., Steel, G., Foreman, J., Penfield, S., Imaizumi, T., Millar, A.J.: Linked circadian outputs control elongation growth and flowering in response to photoperiod and temperature. - Mol. syst. Biol. 11: 776, 2015.

Sehgal, A., Rothenfluh-Hilfiker, A., Hunter-Ensor, M., Chen, Y., Myers, M.P., Young, M.W.: Rhythmic expression of timeless: a basis for promoting circadian cycles in period gene autoregulation. - Science 270: 808-810, 1995.

Simlat, M., Ślęzak, P., Moś, M., Warchoł, M., Skrzypek, E., Ptak, A.: The effect of light quality on seed germination, seedling growth and selected biochemical properties of Stevia 
rebaudiana Bertoni. - Sci. Hort. 211: 295-304, 2016.

Smith, R.W., Helwig, B., Westphal, A.H., Pel, E., Borst, J.W., Fleck, C. : Interactions between phyB and PIF proteins alter thermal reversion reactions in vitro. - Photochem. Photobiol. 93: 1525-1531, 2017.

Song, J., Liu, Q., Hu, B., Wu, W.: Comparative transcriptome profiling of Arabidopsis Col-0 in responses to heat stress under different light conditions. - Plant Growth Regul. 79: 209-218, 2015.

Song, J., Liu, Q., Hu, B., Wu, W. : Photoreceptor PhyB Involved in Arabidopsis temperature perception and heat-tolerance formation. - Int. J. mol. Sci. 18: 1194, 2017.

Song, Y.H., Ito, S., Imaizumi, T.: Flowering time regulation: photoperiod- and temperature-sensing in leaves. - Trends Plant Sci. 18: 575-583, 2013.

Stavang, J.A., Gallego-Bartolome, J., Gomez, M.D., Yoshida, S., Asami, T., Olsen, J. E., Garcia-Martinez, J.L., Alabadi, D., Blazquez, M.A.: Hormonal regulation of temperatureinduced growth in Arabidopsis. - Plant J. 60: 589-601, 2009.

Steinhorst, L., Kudla, J.: Signaling in cells and organisms calcium holds the line. - Curr. Opin. Plant Biol. 22: 14-21, 2014.

Toledo-Ortiz, G., Johansson, H., Lee, K. P., Bou-Torrent, J., Stewart, K., Steel, G., Rodriguez-Concepcion, M., Halliday,
K.J.: The HY5-PIF regulatory module coordinates light and temperature control of photosynthetic gene transcription. PLoS Genet 10: e1004416, 2014.

Tozzi, E., Beckie, H., Weiss, R., Gonzalez-Andujar, J. L., Storkey, J., Cici, S.Z.H., Van Acker, R.C.: Seed germination response to temperature for a range of international populations of Conyza canadensis. - Weed Res 54: 178-185, 2014.

Webb, A.A.R.: The physiology of circadian rhythms in plants. New Phytol. 160: 281-303, 2003.

Wigge, P.A. : Ambient temperature signalling in plants. - Curr. Opin. Plant Biol. 16: 661-666, 2013.

Xin, C., Wang, X., Cai, J., Zhou, Q., Liu, F., Dai, T., Cao, W., Jiang, D.: Changes of transcriptome and proteome are associated with the enhanced post-anthesis high temperature tolerance induced by pre-anthesis heat priming in wheat. Plant Growth Regul. 79: 135-145, 2016.

Xu, F., He, S., Zhang, J., Mao, Z., Wang, W., Li, T., Hua, J., Du, S., Xu, P., Li, L., Lian, H., Yang, H. Q. : Photoactivated CRY1 and phyB interact directly with AUX/IAA proteins to inhibit auxin signaling in Arabidopsis. - Mol. Plants 11: 523-541, 2018.

Yin, R., Ulm, R.: How plants cope with UV-B: from perception to response. - Curr. Opin. Plant Biol. 37: 42-48, 2017. 